\title{
Açıkhava Rekreasyon Kapsamında Milli Park Kullanım Engelleri
}

\author{
Outdoor Recreation: Constraints on Visiting National Parks
}

\author{
Güney ÇETINKAYA* \\ Mustafa YILDIZ ${ }^{* *}$ \\ Mehmet Ali ÖZÇELİK ${ }^{* * *}$
}

Öz: Bu çalışma, açıkhava rekreasyonu ve turizm etkinlikleri için önemli bir kaynak olan milli parkların kullanımlarına yönelik engellerin irdelenmesi amaçlı gerçekleştirilen bir literatür taramasıdır. Günümüzde; milli parklar, bilimsel ve estetik bakımdan, milli ve milletlerarası ender bulunan doğal ve kültürel kaynak değerleri korumanın yanı sıra turizm ve rekreasyon etkinliklerinin gerçekleştirildiği önemli yerler olarak kabul edilmektedir. Bu alanların etkin kullanılması, doğa koruma çalışmalarına katkı sağlarken aynı zamanda fiziksel, sosyal, kültürel, ekonomik ve çevresel anlamda olumlu etkiler yaratmaktadır. Dünya'daki gelişmiş milli park sistemleri incelendiğinde özellikle iç turizme ve rekreasyonel kullanıma yönelik talebin fazla olduğu ve yerel halkın bu alanlardan yüksek düzeyde yararlandığı görülmektedir. Yapılan literatür incelemesi sonucunda, milli parkların kullanımlarına yönelik engeller özelinde yapılmış olan çalışmaların sınırlı olduğu, yapılan çalışmaların da çoğunlukla, yapısal engeller çatısı altında ve etnik azınlıklar üzerine yoğunlaştığ 1 görülmektdir. Bu kapsamda milli park kullanımlarına yönelik engellerin belirlenmesi için yapılacak çalışmaların arttırılması önerilmekte, engellerin belirlenmesiyle de sürdürülebilir milli park planlamalarına destek sağlanması öngörülmektedir.

Anahtar sözcükler: Açıhava Rekreasyonu, Bariyerler/Engeller, Kullanım, Milli Park

\begin{abstract}
The aim of this analysis of the literature was to examine in the context of outdoor recreation the constraits upon visiting national parks. Today, national parks are important areas for tourism and recreation, as well as for the protection of both natural and cultural resources. While the effective use of national parks has a positive impact upon physical, social and cultural well-being, on the economy and the environment, also they contribute in conservation efforts to the protection of nature. Considering the advanced national park system in the world, especially for domestic tourism, and the increasing demand for the recreational use of parks by local people, to take advantage of the high quality of these areas. There is only a limited literature concerning the constraints upon visiting national parks, as most studies concentrate upon the structural constraints and ethnic minorities. In this context, an increase is recommended in studies to be conducted that provide support to sustainable national park planning that are aimed at identifying the constraints upon visiting national parks.
\end{abstract}

Keywords: Outdoor Recreation, Constraints, Visiting, National Park

\footnotetext{
* Yrd. Doç. Dr., Akdeniz Üniversitesi, BESYO, Rekreasyon Bölümü Antalya. gcetinkaya@akdeniz.edu.tr

** Doç. Dr., Akdeniz Üniversitesi, BESYO, Rekreasyon Bölümü, Antalya. mustafayildiz@akdeniz.edu.tr

*** Öğr. Gör., Akdeniz Üniversitesi, BESYO, Rekreasyon Bölümü, Antalya. aliozcelik@akdeniz.edu.tr
} 
"Rekreasyon" insanların günlük yoğun çalışma temposu, alışagelmiş yaşam tarzı veya olumsuz çevresel etkilerden; tehlikeye giren veya olumsuz etkilenen bedeni ve ruhi sağlığını tekrar elde etmek için gerçekleştirilen etkinliklerdir. Bunun yanında zevk ve haz almak amacıyla, kişisel doyum sağlayacak, tamamen çalışma ve zorunlu ihtiyaçlar için ayrılan zaman dışında kalan, bağımsız ve kendisine ait serbest zamanda isteğe bağlı ve gönüllü olarak ferdi veya grup içinde seçerek yaptığı etkinliklere rekreasyon denmektedir (Hacıoğlu et al. 2003, 30). Modern anlamda serbest zaman kavramının ortaya çıkışı ve gelişimi endüstri toplumunun ortaya çıkışı ve gelişimi ile ilintilidir. Özellikle son yüzyıldaki endüstrileşme süreci; insanların yaşam koşullarında önemli değişimlere neden olarak, insanların rekreasyon ihtiyacını şekillendirmiştir. Günümüzde, rekreasyon etkinliklerinin büyük bir kısmı doğada meydana gelirken, kaynak olarak çoğunlukla doğal kaynakları kullanılmaktadır (Karaküçük 1999, 214). Doğada ve açıkhavada gerçekleşen etkinliklerin çoğunluğu, endüstrileşmiş toplumun bir ürünü olan açıkhava rekreasyonu ve doğa turizmi kavramları ile tanımlanmaktadır. Akesen'e göre (1982) açıkhava rekreasyonu, bireylerin ve toplumların rekreasyonel gereksinimlerini karşılama amacıyla doğa üzerinde oluşturdukları bir çeşit kaynak kullanma biçimidir. Özellikle sanayi devriminden sonraki süreçte, çalışma koşullarındaki ve yaşam biçimindeki köklü değişimler, bireylerin ve toplumların doğal kaynak kullanımına olan ihtiyacında değişikliklere neden olmuştur. Bu değişimler, park ve açıkhava rekreasyonu kavramlarının çağdaş toplumlarda önemini giderek arttırmıştır. Cordell'e göre (2008) özellikle Büyük Buhranın ve 2. Dünya Savaşının ardından açıkhava rekreasyonu Amerikan yaşam tarzının temel bileşeni olarak ortaya çıkmıştır. 1960-1980 yılları arasında, açıkhava rekreasyonuna katılım önemli derecede artış göstermiştir. Günümüzde ise bu kavram, birçok insanın yaşamının vazgeçilmez önemli bir unsuru olarak tanımlanmaktadır. Amerika Açıkhava Katılım Raporu (2012) bu durumun bir göstergesi olarak görülebilir. Bu rapora göre Amerika nüfusunun yaklaşık \%50'sinin açıkhava rekreasyonu etkinliklerine katılmakta, 6.1 milyon Amerikalı açıkhava rekreasyonu alanında istihdam edilmekte ve açıkhava endüstrisi 640 milyar doların üzerinde bir ekonomi yaratmaktadır (Outdoor Industry Association 2012). Endüstri devriminin çıkış noktası olarak kabul edilen İngiltere'de ise her dört yetişkin bireyden üçünün aktif olarak açıkhava rekreasyonu etkinliklerine katıldığı, bu bireylerin 21 milyar İngiliz Sterlin harcama yaptığı ve bu etkinlikler kaynaklı olarak yaklaşık 245.000 kişiye tam zamanlı iş olanağ sunduğu görülmektedir (Reconomics 2014). Günümüzde birçok ülke için açıkhava rekreasyonu önemli bir sektördür. Açıkhava rekreasyonu ile ilgili literatür incelendiğinde bu kavram ile ilgili çalışmalarının çoğunlukla spesifik bir açıkhava rekreasyonu etkinliğinin çevre ve ekoloji üzerine yoğunlaştığı görülmektedir (Cole 1989). Ancak açıkhava rekreasyon etkinliklerinin ekonomik, fiziksel, psikolojik, sosyal ve kültürel birçok etkileri bulunmaktadır. Açıkhava rekreasyonu etkinliklerinin katılımcısına yönelik fiziksel etkilerini; obeziteyi azaltma (Welk \& Blair 2000), kronik rahatsızlıklar ile mücadele etme (Haennel \& Lemire 2002), bağışıklık sistemini güçlendirme (Tarrant et al. 1994) olarak sinıflamak mümkündür. Ayrıca, bu etkinliklerin, depresyonu ve stresi azaltma, yaşam kalitesini arttırma gibi psikolojik sağlıkla ilgili olumlu etkileri ve çeşitli toplumsal faydaları da bulunmaktadır. Bu faydaları, suç oranını azaltma, gönüllü etkinliklere dâhil olmayı teşvik etme gibi toplumu güçlendirici; aileleri birleştirme, kültürel çeşitliliği inşa etme, yaşlıları ve engellileri destekleme gibi sosyal bağ arttırıcı; gençliği desteklemek, olumsuz davranışları engellemek, madde bağımlılığını azaltmak gibi gençliği destekleyici etkiler olarak sinıflamak mümkündür (Anonim 2005).

\section{Milli Park ve Rekreasyon İlişkisi}

Açıkhava rekreasyon etkinlikleri çoğunlukla doğal alanlarda gerçekleştirilen etkinliklerdir, bu alanların çeşitli sınıflandırmaları bulunmaktadır ve bu alanların sınıflandırılması ülkeden ülkeye 
farklılıklar göstermektedir. Bu sinıflamalardan en fazla kabul görüp, uygulananı ise Dünya Korunma Birliği (IUCN) tarafından yapılan sınıflamadır. Bu sınıflamaya göre, doğal alanlar; I) a-Mutlak Doğa Rezervi / b-Kırsal alanlar, II) Milli Parklar, III) Doğal Anıtlar, IV) Habitat/türlerin Yönetim Alanı, V) Peyzaj Koruma Alanları ve VI) Yönetilen Kaynak Koruma Alanlarıdır (www.iucn.org). IUCN'nın yapmış olduğu sınıflama çerçevesindeki bulunan her bir alanın kuruluşundaki temel amaçta belirlenmiştir. Tablo 1'de görüldüğü üzere turizm ve rekreasyon etkinlikleri birçok doğal alan için önemli bir amaç niteliği taşımaktadır.

Tablo 1. IUCN'e göre Doğal Alanların Yönetimsel Amaçları

\begin{tabular}{|l|c|c|c|c|c|c|c|}
\hline Yönetimsel Amaç & I-a & I-b & II & III & IV & V & VI \\
\hline Bilimsel araştırma & 1 & 3 & 2 & 2 & 2 & 2 & 3 \\
\hline Vahşi yaşamı koruma & 2 & 1 & 2 & 3 & 3 & - & 2 \\
\hline Genetik çeşitliliğin ve türlerin korunması & 1 & 2 & 1 & 1 & 1 & 2 & 1 \\
\hline Çevresel hizmetlerin bakımı & 2 & 1 & 1 & - & 1 & 2 & 1 \\
\hline Doğal/Kültürel özellikli türlerin korunması & - & - & 2 & 1 & 3 & 1 & 3 \\
\hline Turizm ve Rekreasyon & - & $\mathbf{2}$ & $\mathbf{1}$ & $\mathbf{1}$ & $\mathbf{3}$ & $\mathbf{1}$ & $\mathbf{3}$ \\
\hline Eğitim & - & - & 2 & 2 & 2 & 2 & 3 \\
\hline Doğal ekosistemlerin sürdürülebilir kullanımı & - & 3 & 3 & - & 2 & 2 & 1 \\
\hline Kültürel/geleneksel özelliklerin bakımı & - & - & - & - & - & 1 & 2 \\
\hline
\end{tabular}

Anahtar: 1 Birincil amaç, 2 İkincil amaç, 3 Potansiyel Uygulanabilir - Uygulanamaz amaç

Kaynak: IUCN 1999, Akt. Taylor 2004.

Açıkhava rekreasyon faaliyetlerinin yürütüldüğü doğal alanların en yaygın olanı, milli parklardır ve bu alanların kuruluş esasını; doğal güzellikler ve kültürel özellikler taşıyan yerlerin, kendi doğal koşulları içinde korunması, sosyal, kültürel ve turistik amaçlarla insan faydalanımına açılması oluşturmaktadır (Doğaner 1985). Ülkemizde 1983 yılında yürürlüğe giren 2873 numaralı Milli Parklar Kanununa göre bu alanlar "bilimsel ve estetik bakımından, milli ve milletlerarası ender bulunan tabii ve kültürel kaynak değerleri ile koruma, dinlenme ve turizm alanlarına sahip tabiat parçalarıdı" (www.mevzuat.gov.tr). Milli parkların temel amacı, belirli özelliklere sahip olan alanları korumaktır. Ancak yapılan tanımdan da anlaşılacağı üzere bu alanların koruma amacının dışında yaygın olarak rekreasyonel ve turistik amaçlı olarak kullanılması da söz konusudur. Amerika Birleşik Devletleri'nde, 1900'lü yılların başlarında milli park tasarımlarında rekreasyon kavramının temel rol oynadığı görülmektedir (Harrison \& Erpelding 2012). Günümüzde açıkhava rekreasyonu etkinliklerinin gerçekleştirildiği en önemli alanlardan biri olan milli parkların, rekreasyonel amaçlı olarak kullanılması giderek daha yaygın hale gelmiştir. IUCN'de turizm ve rekreasyon faaliyetlerinin milli parklar için öncelikli amaçlardan biri olduğunu vurgulamaktadır.

Milli parklar; yeşil ve açık alan sunarken; günümüz hareketli yaşamını yavaşlatır, doğal alanlardaki vahşi yaşamı korur, ayrıca bu alanlar toplumun önemli göstergeleri olan tarihi ve kültürel kaynakların bir sonraki nesle bozulmadan aktarılmasını destekler. Bu nedenle de milli park kavramı, insanlar için yaşamsal olarak kabul edilmektedir. Günümüz modern toplumlarında milli parklar, doğal ve kültürel kaynakları koruyarak artan nüfusa rekreasyon firsatı sunar ve yaşam kalitesini arttırır (Manning et al. 1998). Manning ve Anderson'a (2012) göre bu alanlar; sağlıklı ve memnuniyet verici serbest zaman aktiviteleri sunduğu, doğa ile kontak 
kurmasını sağladığı, aile birliğinin kurulması firsatı yarattı̆̆ı, kültürel miras ve doğal çevrenin değerlendirilmesine olanak sağladığı içinde oldukça önemli kabul edilmektedir. Bu kavram, alan kullanımının "yeni bir formu" olarak Amerika Birleşik Devletlerinde ortaya çıkmış (Runte 2010) ve 1872 'de ilk milli park olan "Yellowstone Milli Parkının" ilan edilmesiyle uygulamaya geçmiştir. ABD'de ortaya çıkan milli parkçılık kavramı, 19. yüzyıl sona ermeden Avustralya, Kanada, Yeni Zelanda ve Meksika tarafından da kabul görmüş, 1900'lü yılların başlarında ise Avrupa'ya yayılmaya başlamıştır. Dünya' da bu yayılım giderek artış göstermiş (Tablo 2); 1914 yılında 40 adet olan milli park sayısı, 1939 yılında 300, 1971 yılında yaklaşık 1200 ve 2003 yılında ise 8800'e ulaşmıştır (Yücel \& Babuş 2005). Türkiye'de ise milli park çalışmaları, 1956 yılında yürürlüğe giren 6831 sayılı Orman Kanununun 25.maddesi ile yasal bir uygulama alanı bulmuş, ancak ayrı bir hukuki statüye kavuşması 1983 yılında çıkarılan 2873 sayılı milli parklar kanunu ile gerçekleşmiştir. Güncel verilere göre, 1958 yılında ilk milli parkın ilanından günümüze milli park sayısı 40'a ulaşmıştır (www.milliparklar.gov.tr).

Tablo 2. Çeşitli Ülkelerdeki Milli Parkların Sayısı, Toplam Alanları, Ülke Yüzölçümüne Oranları

\begin{tabular}{|l|c|c|c|}
\hline Ülke Adı & $\begin{array}{c}\text { Milli Park } \\
\text { Sayısı } \\
\text { Adet }\end{array}$ & $\begin{array}{c}\text { Milli Parkların } \\
\text { Toplam Alanı } \\
\text { (ha) }\end{array}$ & $\begin{array}{c}\text { Milli Parkların Ülke } \\
\text { Yüzölçümüne } \\
\text { Oranı (\%) }\end{array}$ \\
\hline ABD & 805 & 54.317 .500 & 15.5 \\
\hline Avustralya & 2.295 & 43.695 .300 & 7.5 \\
\hline Azerbaycan & 12 & 74.300 & 4.6 \\
\hline Brezilya & 312 & 20.972 .600 & 18.0 \\
\hline Bulgaristan & 54 & 75.100 & 10.1 \\
\hline Çin & 54 & 44.939 .300 & 7.8 \\
\hline Kanada & 1.816 & 45.636 .200 & 6.3 \\
\hline Yunanistan & 13 & 79.200 & 3.2 \\
\hline İran & 16 & 1.619 .800 & 6.5 \\
\hline İspanya & 34 & 160.400 & 9.2 \\
\hline Japonya & 53 & 637.800 & 14.0 \\
\hline Pakistan & 5 & 714.500 & 9.2 \\
\hline Rusya & 108 & 25.203 .200 & 7.6 \\
\hline Türkiye & 33 & 686.486 & 0.8 \\
\hline Dünya & $\mathbf{8 . 8 0 0}$ & $\mathbf{4 3 8 . 4 4 8 . 0 0 0}$ & $\mathbf{1 0 . 8}$ \\
\hline
\end{tabular}

Kaynak: Earth Trend 2004, Akt. Çetinkaya 2008.

Milli parkçılığın dünyadaki gelişimi, taşıdığı anlam ve önem ülkeden ülkeye farklılık gösterebilmekle birlikte temel amaç; bu alanların korunarak gelecek nesillere aktarılmasıdır (Demir 2001). İlk milli park ilanından günümüze, bu alanların rekreasyonel ve turistik amaçlı olarak kullanılmasına yönelik düzenlemeler yapılarak, bu alanların gerçekleştirecek etkinliklere hazır hale getirilmesi sağlanmaktadır. Bu hazırlıkları tamamlayan ülkelerin, yerli ve yabancı ziyaretçi sayısı katlanarak artmaktadır. Korunan alanlarda ve özellikle milli parklarda gerçekleştirilen turizm etkinliklerinin, ekonomik anlamda olanakları arttırdığı, doğal ve kültürel mirası koruduğu ve yaşam kalitesini arttırdığı savunulmaktadır (Tablo 3) (Eagles \& McCool 2002).

Tablo 3. Korunan Alanlarda Turizmin Potansiyel Faydaları

\section{Ekonomik Olanaklara Yönelik Faydaların Yaratılması}

- Yerel halk için iş imkânlarını arttırır.

- Geliri arttırir.

- Yerel ekonomiyi çeşitlendirir ve yeni turizm girişimlerini özendirir. 
- Yerel ürünlerin üretimini cesaretlendirir.

- Yeni pazarlar ve döviz sağlar.

- Yaşam standartlarını arttırır.

- Yerel vergi gelirleri yaratır.

- Çalışanların yeni beceriler edinmesine olanak verir.

- Yerel topluluklar ve koruma alanları için fonları arttırır.

\section{Doğal ve Kültürel Mirası Koruma}

- Ekolojik süreçleri korur.

- Biyo-çeşitliliği korur.

- Kültürel mirası korur.

- Ekonomik değer yaratır ve kaynakları korur.

- Eğitim vasitasıyla korunan değerleri aktarır.

- Ziyaret edilen yerdeki yerli halk ve ziyaretçilerin kültürel mirasının, doğal ve inşa edilmiş varlıkların anlaşılmasına ve iletişime geçilmesine yardım eder. Böylece yeni sorumlu tüketici nesli inşa edilir.

- İyi çevresel uygulamaların gelişmesi ve araştırılması desteklenir.

- Yerel olanakları, taşıma sistemlerini ve haberleşmeyi geliştirir.

- Korunan alan operasyonların için kendini finanse etme mekanizmalarının gelişmesine yardim eder.

\section{Yaşam Kalitesini Arttırma}

- Sağl1kla ilgili değerleri teşvik eder.

- Ziyaretçiler ve yerel halk için çevresel eğitimi destekler.

- Uygun yeni aktivitelerle, ziyaretçilere olduğu kadar yerel halk içinde çevresel çekiciliği arttırır.

- Kültürlerarası anlayışı geliştirir.

- Sanatın, el sanatlarının ve kültürün gelişmesini cesaretlendirir.

- Yerel halkın eğitim düzeyini arttırır.

- Yerel halkı yabancı turistlerin kültürlerini ve dillerini öğrenmek konusunda cesaretlendirir.

- Yerel halkı kendi kültürlerinin ve çevrelerinin değerlerini bilmeleri konusunda cesaretlendirir.

Kaynak: Eagles \& McCool 2002.

Endüstrileşen turizm; günümüzde dünya gayri safi yurtiçi hasılasına ve istihdamına direkt olarak katkı sağlayan önemli bir sektördür. 2014 yılı verilerine göre turizm ve seyahat endüstrisi küresel ekonomiye 7.6 trilyon dolar katkı sağlayarak toplam gayri safi yurtiçi hasılasının \%9.8'ini oluşturmuştur (WTTC 2015). Kırsal ve korunan alanlarda gerçekleşen turizm etkinlikleri ise, turizm endüstrisi içerisinde önemli yer tutamaktadır. Dünya Kaynakları Enstitüsü raporuna göre turizm endüstrisinin dünyadaki y1llık büyüme oranı \%4'ken, doğa temelli turizm endüstrisinin büyüme oranı \%10-20 arasındadır (NETSAP 2004). Turizm amaçlı kullanılan milli parklar; Doğu ve Güney Afrika, Kosta Riko, Ekvator, Hindistan, Nepal, Endonezya, birçok Asya ve Güney Amerika ülkelerinin önemli gelir kaynaklarıdır. Örneğin; Kenya, turizm gelirlerinin büyük bir kısmı ülkedeki milli parklardan ve koruma alanlarından elde edilmektedir (Demir 2001). Nepal'in gayri safi milli hasılasının \%3.8'i ve toplam döviz 
girdisinin \%18'ini milli park gelirleri oluşturmaktadır (Nepal 2000). Milli Park fikrinin ortaya çıktığı ve "Şimdiye kadar ki en iyi fikir" olarak tanımlandığ 1 (Dilsaver 1994; Le \& Holmes 2012; Weber \& Sultana 2013) yer olan, Amerika Birleşik Devletleri 2014 y1lı verilerine göre, Milli Park Servisine bağlı alanların yıllık ekonomiye katkısı 27 milyar dolar civarındadır ve bu alanlar, 240.000 den fazla yerel iş olanağı sunmaktadır (www.nps.gov). Bu makro etkilerin dışında milli parklarda yapılan turizm etkinliklerinin bölgesel anlamda da ekonomik etkileri bulunmaktadır. Amerika, Kanada ve Almanya'da yapılan çalışmada, milli parkları ziyaret eden turistlerin, parkların bulundukları bölgede önemli ekonomik etki yarattıkları belirlenmiştir (Eagles et al. 2000; Mayer et al. 2010). Örneğin, 13 milli parkın bulunduğu İspanya'daki, milli parkları yılda yaklaşık 11 milyon kişi ziyaret etmektedir. Bu ziyaretçi sayısı ülkeye gelen turistlerin yaklaşık, 3'te 1, bölgede yaşayan nüfusun 10 katı olup bölgedeki yaşayan yerel halk1 sosyoekonomik açıdan etkilemektedir (Voth 2012). Yukarıdaki örneklerden yola çıkarak, turizm amaçlı kullanılan milli parkların; gelişmiş, gelişmekte olan ve az gelişmiş ülkelerin her biri için önemli bir ekonomik değer olduğunu söylemek mümkündür. Bu alanların yarattı̆g 1 ekonomik etkileri Dünya Turizm Örgütü (WTO) ve Birleşmiş Milletler Çevre Programı (UNEP) aşağıdaki gibi sınıflamıştır (Demir 2001).

- Döviz kazancı yaratır.

- Dolaylı ve dolaysız olmak üzere istihdam yaratır.

- Özellikle tarımsal istihdamın yetersiz ve geçici olduğu kırsal kesimlerde yerel ekonomileri çeşitlendirir.

- Oteller, restoranlar, ulaştırma kuruluşları, hediyelik eşya, el sanatları ve rehberlik hizmetleri gibi karlı yerel endüstrileri teşvik eder.

- Yerel ulaştırma ve haberleşme altyapısının gelişmesini teşvik ederek yerel halka fayda sağlar.

- Uygun bir şekilde gerçekleştirildiğinde, park otoritelerinin parkı kendi kendine finanse edebilen hale getirmelerini sağlar ve buna bağlı olarak da doğal mirasın korunması için bir araç teşkil eder.

- Global iletişimi ve kültürel anlamayı geliştirir.

- Turizm için geliştirilecek koruma alanları bir bölge için model oluşturuyorsa yerel yönetimler, gelişmenin çevre illeri de kapsaması için kaynak yaratılmasına daha istekli olabilirler.

- Tarım faaliyetleri için marjinal olan alanların verimli bir şekilde kullanımını teşvik eder.

- Yerel halk, yerli ve yabancı turistler tarafindan kullanılabilen tesislerin yaratılmasını sağlar.

- Hükümet yetkililerini ve yerel halkı, doğal alanları korumanın önemi konularında bilinçlendirerek bu alanların korunmalarını sağlar.

Milli park ve eşdeğer rezervlerin yarattığı etkiler sadece ekonomik değildir ve bu etkileri sadece ekonomik değer olarak algılamamak gerekir. İlgili literatür incelendiğinde, milli parkların etkilerinin ekonomik olan etkiler dışında, çevresel, sosyal ve kültürel olarak sınıflandığını görmek mümkündür. Eagles ve McCool (2004) milli parkların yarattığı etkileri sinıflandırırken, olumlu veya olumsuz etki kavramlarının yüksek düzeyde sübjektif ve durumsal olduğunu vurgulamış ve herhangi bir etki birine göre olumluyken, bir diğerine göre olumsuz olabileceğini ya da herhangi biri için bir dönem olumlu yada olumsuz olan etkinin, başka bir dönem de yine aynı kişi için olumsuz ya da olumlu olabileceğini savunmuştur. Bu sav göz önünde bulundurulduğunda, milli parkların yarattığı etkileri, çevresel etkiler başta olmak üzere, sosyal, 
kültürel ve ekonomik olarak sınıflandırmanın daha uygun olacağı düşünülmektedir.

Milli parkın bir diğer önemli kullanım türü rekreasyoneldir. Gerçekte, Milli Park alanlarının turistik ve rekreatif kullanımı birbirine paralellik göstermekte ve bu iki kavram çoğunlukla beraber değerlendirilmektedir. Bu anlamda, milli parkların turistik amaçlı yoğun kullanıldığ ülkelerde, bu alanların aynı zamanda rekreasyonel amaçlı da yoğun kullanıldığı söylenebilir. Örneğin, turistik olarak milli parkların yoğun kullanıldığı Amerika Birleşik Devletleri'nde, Amerikan Seyahat Birliği (2014) raporuna göre son 5 yılda yetişkin Amerikalıların \%40'ı en az bir kere milli park ziyaret etmiş ve bu ziyaretlerin \%75'i ziyaret ettikleri milli parklarda konaklamıştır (Miller \& Washington 2014). Günümüzde Amerika Birleşik Devletlerindeki milli parkları ziyaret eden yıllık ziyaretçi sayısı 280 milyon kişiye (www.statista.com) ulaşmıştır. $\mathrm{Bu}$ ülkenin nüfusunun 300 milyon civarında olduğu göz önüne bulundurulduğunda bir kişinin her y1l bir defa milli park ziyaretinde bulunduğu söylenebilir. Yaklaşık nüfusu 63 milyon kişi (www.ons.gov.uk) olan İngiltere'de de benzer bir durumdan söz edilebilir. Park alanlarının, birçok farklı girişi olması, kontrol noktalarının az olması ve bölgede çok sayıda insan yaşamasından dolayı tam olarak bir sayı verilememesine rağmen, İngiltere'deki milli parkları ziyaret eden kişi sayısı 76 milyona ulaştığı tahmin edilmektedir (Eagles \& McCool 2002). Türkiye’de de milli park kullanımına yönelik talebin gelişim gösterdiği söylenebilir. Bu alanların kullanımlarına ait veriler incelendiğinde, özellikle son 10-15 yıllık periyotta milli park ziyeretçi sayıları artış gösterdiği görülmektedir. Ancak, yaklaşık nüfusu 78 milyon olan ve yılda ortalama 40 milyon turistin geldiği Türkiye'de (UNWTO 2015) yıllık milli park ziyaretçi sayısının 13 milyon (www.milliparklar.gov.tr) dolaylarında olması, bu alalanlardan yeterince yararlanılmadığı düşüncesini doğurmaktadır.

\section{Açıkhava Rekreasyonu Engelleri}

Serbest zaman engelleri "insanların; serbest zaman aktivitelerine katılımı, serbest zaman servislerini kullanımı veya aktivitelerden keyif almaların sinırlayan faktörler olarak" tanımlanmaktadır (Jackson \& Scott 1999). Özellikle 1980'lerin başlarında serbest zaman engelleri çalışmaları gerçekleştirilmeye başlanmıştır. Bu aşamada serbest zaman engelleri; bariyerler, önleyiciler, engelleyiciler veya kısıtlayıcı faktörler olarak adlandırılmıştır. Çeşitli yazarlara göre, engeller birbirleriyle ilişkili ve boyutlu olarak değerlendirilmelidir (Thapa et al. 2002). Bu çerçevede Jackson'a (1993) göre engeller, (a) sosyalizolasyon, (b) ulaşılabilirlik, (c) kişisel nedenler, (d) maliyet, (e) zaman ve (f) olanaklar olmak üzere 6 boyutta sinıflandırılmıştır. Ancak engeller ile ilgili en tanınmış ve bilinen sınıflandırma Crawford ve diğ. (1991) tarafından yapılan hiyerarşik modeldir (Figür 1) (Shores et al. 2007). Bu hiyerarşik modele göre; serbest zaman engelleri, kişisel (intrapersonal), kişilerarası (interpersonal) ve yapısal (structural) engeller olarak üç kategoride değerlendirilmektedir. Kişisel engeller, serbest zaman tercihlerini etkileyen; stres, korku, utanç, depresyon, anksiyete, grup tutumları, algılanan beceri ve çeşitli serbest zaman aktivitelerine yönelik algılanan uygunluğu içeren bireysel psikolojik özellikler olarak tanımlanmaktadır (Crawford et al. 1991). Kişilerarası engeller, serbest zaman etkinliklerinin ortaya çıktığı sosyal ortamın uygunluğu ile ilgili olup, sosyal faktörler olarak tanımlanmaktadır. Raymore et al. (1993)'ne göre bireyler aile, arkadaş, eş veya başka insanlar tarafından olumsuz şekilde etkileniyorsa burada toplumsal bir kısıtlamadan söz edilmelidir (Akt. Öcal 2012). Yapısal engeller ise, finansal kaynaklar, zaman, ulaşım, firsatların uygunluğu, aile yaşam döngüsü, mevsim, iş yaşam ve iklim gibi dış kaynaklıdır. Crawford et al. (1991) yapmış olduğu çalı̧̧mada, bireysel ve toplumsal engellerin daha çok serbest zaman aktivitelerini seçme sırasında, yapısal engellerin ise daha çok yapılan seçimlere katılım aşamasında etkili olduğu belirlenmiştir. Yine aynı araştırmaya göre bireysel engeller serbest zaman engelleri içerisinde en 
kuvvetli olanken, yapısal engeller de en az kuvvete sahip olan engel olduğu belirlenmiştir.

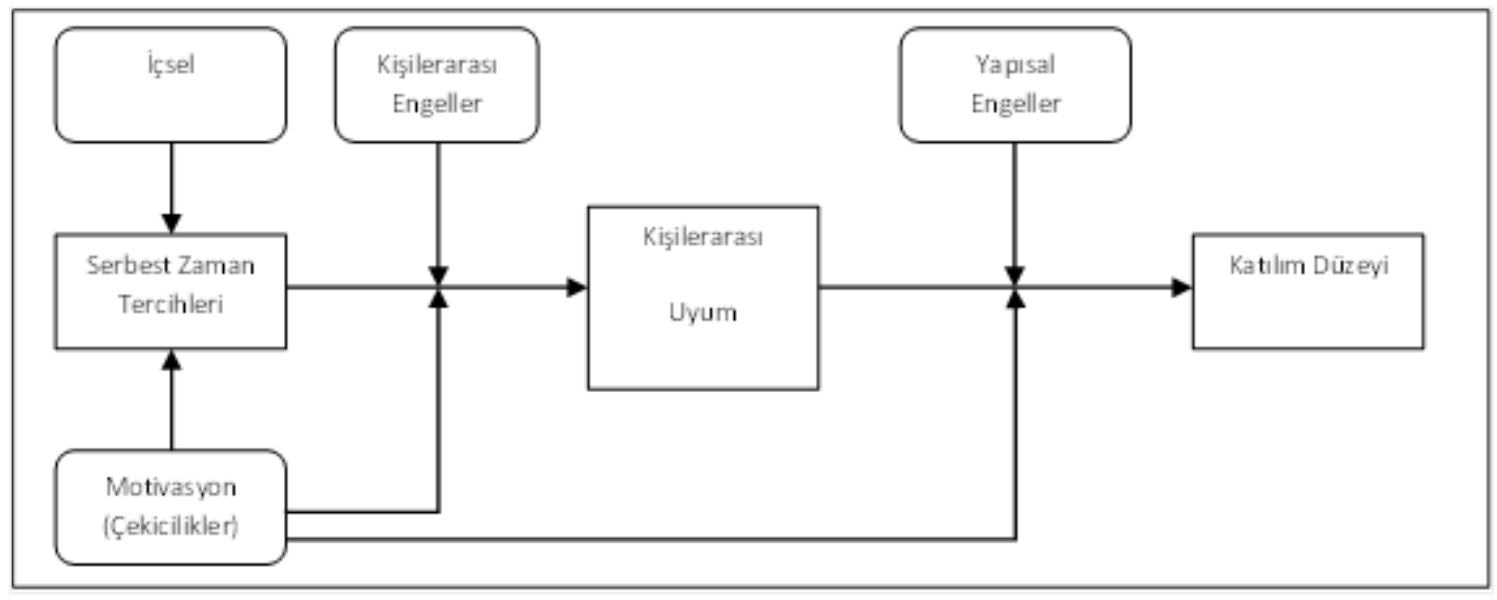

Fig. 1. Serbest Zaman Engelleri Hiyerarşik Modeli (Caber \& Albayrak 2006)

Serbest zaman engelleri, psikolojik, sosyal, antropolojik vb. birçok nedenden dolayı bu etkinliklere katılan bireylerin katılımın etkilemektedir. Bu sebeple, serbest zaman engelleri çalışmalarının, sosyal bilimlerin birçok alanı ile ilişkili olduğu söylenebilir. Walker ve Virden'e (2005) göre serbest zaman engelleri ile açıkhava rekreasyonu araştırmaları alanlarının kavramsal özellikleri temel alındığında, her iki alanın etkileşimleri fayda yaratmaktadır ancak bu iki alanın örtüştüğü noktalar oldukça sınırlıdır. Gerçekte, serbest zaman engelleri araştırmaları rekreasyon araştırmacılarına sadece yararlı bilgiler sağlamamaktadır, bunun yanında korunan alan yöneticilerinin karar vermelerini de desteklemektedir. Ayrıca Serbest zaman engelleri araştırma sonuçları rekreasyon yönetimi stratejilerinde doğrudan uygulanabilir ve serbest zaman etkinliklerine katılımın kalitesini arttırabilir (Boothy et al. 1981). Bu anlamda, serbest zaman engellerinin ortaya çıkarılması, rekreasyon yönetim süreçlerini etkileyerek, şekillendirdiği ve rekreasyon etkinliklerinin verimini arttırmaya fayda sağladığı düşünülmektedir.

Açıkhava rekreasyonu engelleri çalışmaları ile serbest zaman engelleri çalışmalarının gelişimi benzerlik göstermektedir. Yapılan çalışmaların çoğunluğunda serbest zaman engelleri modeli sınanmıştır. Walker ve Virden (2005) yaptıkları çalışmada Serbest Zaman Engelleri Modelinin yapısal engeller boyutuna ilave olarak açıkhava rekreasyonu kavramına ait yeni dört boyut önermiştir.

- Doğal Çevre; doğal çevre koşullarından dolayı katılımın sınırlanması,

- Sosyal Çevre; kalabalık gibi sosyal çevre koşullarından dolayı katılımın sinırlanmasi,

- Bölgesel; ulaşılabilirlik nedenlerinden dolayı katılımın sınırlanması,

- Kurumsal; acenta veya yönetimsel güç kaynaklı engellerden dolayı katılımın sinırlanmas1 (White \& Bustam 2010).

Walker ve Virden (2005) Kuzey Amerika'da gerçekleştirilen geniş ölçekli dört çalışmayı özetlemiştir. Bu çalı̧̧malara göre, açıkhava rekreasyonu etkinliklerine katılımını, bilgilendirme eksikliği, rekreasyon alanının uzaklığı, ailevi yükümlülükler, sağlık problemleri olan aile bireyleri, açıkhava rekreasyon etkinliklerine katılmak için bütçenin ve etkinliğe katılacak arkadaşın olmaması faktörlerinin yüksek düzeyde, suç korkusu, malzeme eksikliği, yüksek giriş ücretleri ve alanların bakımsızlığının orta düzeyde engellemektedir (Shores et al. 2007).

1970’lerde başlamış olan serbest zaman engelleri çalışmaları, 1990'larda sayısını attırarak 
günümüze kadar gelmiştir. Yapılan öncül çalışmalar, ırk veya cinsiyet ayrımına odaklanırken, güncel çalışmalar ırk veya cinsiyet farklılıklarına ek olarak, sosyoekonomik ve gelir, eğitim seviyesi, yerleşim yeri gibi demografik faktörleri içine alacak biçimde genişlemiştir. Buna ilave olarak, bazı araştırmalar, sosyal eşitsizliğin toplumda önem derecesi düşük olan grupların açıkhava rekreasyonu etkinliklerine katılımını nasıl etkilediğini araştırmıştır. Ancak, yapılan birçok çalışma, örneklem büyüklükleri ve coğrafi kapsamı açısından etnik azınlıklar ve sosyal olarak marjinal olan gruplarla sınırlı kalmıştır (Ghimire et al. 2014). İlgili ilteratür incelendiğinde serbest zaman ve açıkhava rekreasyonu engelleri, çeşitli faktörler ile ilişkilendirilmiştir. Bu faktörler aşağıdaki biçimde özetlenebilir.

\section{a) Sosyo-ekonomik Durum}

Kültürel ve etnik köken faktörleri yüzünden sosyo-ekonomik değişkenler 1980'lere kadar serbest zaman etkinliklerine katılımı etkileyen göstergeler olarak geniş bir biçimde kullanılmamıştır. Ancak bu durum sosyo-ekonomik durumun insanların serbest zaman etkinliklerine katılımı için önemsiz bir etken olduğu anlamına gelmemelidir. Gerçekte, gelir düzeyi, eğitim seviyesi ve meslek serbest zaman etkinliklerine katılımı önemli derecede etkilemektedir (Lee et al. 2001). Çoğu açıkhava rekreasyonu aktiviteleri finansal ve kültürel kaynağa bağlıdır ve gelireğitim düzeyi açıkhava etkinliklerine katılımı etkilemektedir (Ghimire et al. 2014). Örneğin, Clarke (1956) ve Burdge (1969) meslek ile serbest zaman etkinliklerine katılım arasında önemli bir ilişki olduğunu bulmuştur (Akt. Ghimire et al. 2014). Kelly (1996) gelir ve mesleğin, serbest zaman etkinliklerine katılım firsatlarını ve sınırlılıklarını etkilediğini vurgulamaktadır. Aynı çerçevede Scott ve Munson (1994) çalışmasına göre gelir, park ziyaretini kısıtlayan en önemli göstergedir. Kelly (1980; 1996) eğitim düzeyinin, gelir veya mesleğe göre serbest zaman etkinliklerine katılımı etkileyen daha önemli bir gösterge olduğunu vurgulamıştır. Bu durumun nedenini, üniversite eğitimi alan kişilerin, Açıkhava rekreasyonuna yönelik becerilere, bilgilere ulaşabilecekleri sosyal ve kültürel çevreye ulaşımlarının daha kolay olabileceği örneği ile açıklamıştır (Lee et al. 2001). Alexandris ve Carroll (1997) tarafından yapılan çalışmada Kelly'nin çalışmaları ile benzerlik göstererek düşük eğitim seviyesindeki kişilerin engel algılarında artış olduğu biçimindedir.

\section{b) Yaş}

Serbest zaman davranışını etkileyen bir diğer önemli faktör katılımcıların yaşıdır. Yapılan araştırmalar, yaşlı bireylerin fiziksel kısıtlayıcılarından ve yaşlılıktan dolayı Açıkhava rekreasyon etkinliklerine daha az katıldıklarını göstermektedir (Iso-Ahola et al. 1994). Ayrıca, yaşlı bireylerin, genç bireylere oranla park kullanımına yönelik daha fazla engellere sahip olduğu belirlenmiştir (McGuire, Boyd \& Tedrick 1996; Scott \& Jacson 1996; Raymore \& Scott 1998). Yaşlanma kaynaklı olarak, fiziksel kısıtlayıcıların artmasıyla, bireylerin aktif olarak katıldıkları rekreasyon etkinlikleri azalmakta, bireyler daha pasif etkinlikleri tercih etmektedir (Floyd et al. 2006). Shores et al. (2007) yaş ile açıkhava rekreasyon engelleri ilişkisini açıklarken, finansal yapının iyi anlaşılması gerektiğini vurgulamıştır. Yazarlar, (Amerika'da) yaşlı bireylerin geçtiğimiz kuşaklara göre daha sağlıklı olmasına rağmen, \%20'sinden fazlasının yalnız ve fakirlik sınırlarında yaşadığını belirtmiştir. Bu durumunda rekreasyon etkinliklerine katılımı ve bu etkinliklere yönelik engelleri etkilediği düşünülmektedir.

\section{c) Cinsiyet}

Serbest zaman etkinliklerine katılım engelleri hem erkek hem de kadınları etkilemesine rağmen, yapılan çalışmalar serbest zaman engelleri konusunda, kadınların erkeklere göre daha farklı ve daha fazla engellere sahip olduğunu göstermektedir (Shores et al. 2007). Bu durumun nedeninin 
kadının toplumdaki rollerinden kaynaklı olduğu düşünülmektedir. Rojek (1985) bu konuda kadınların açıkhava rekreasyonu etkinliklerine katılımında bir takım özel sınırlılıklara sahip olduğunu vurgulamaktadır ve bu sinırlılıkları erkek egemen toplum yapısında kadının rolleri ve kadınların cinsel obje olmasıyla ilişkilendirmektedir (Akt. Ghimire et al. 2014). Ayrıca, kadınların erkeklere göre açıkhava etkinlikleri tercihlerinde farklılıklar bulunmaktadır. Lee ve diğ. (2001) yaptığ çalışmaya göre, kadınlar aile ile ve ev işleri ile ilgili sosyal toplantıları açıkhava rekreasyon etkinliklerine oranla daha fazla tercih etmektedir. Kadınlara yönelik başka bir engel ise güvenlik ile ilgilidir. Yapılan çalışmalar, kadınların güvenlik konularına erkeklerden daha fazla odaklandığını belirtmektedir (Ghimire et al. 2014).

\section{d) Irk ve Etnik Köken}

İlgili literatür incelendiğinde azınlıkların açıkhava rekreasyonu etkinliklerine katılım düzeylerinin düşük olduğu ileri sürülmektedir. Buna ilave olarak azınlıkların/göçmenlerin açıkhava rekreasyonu etkinliklerine katılımda daha fazla engelle karşılaştığı vurgulanmaktadır (Ghimire et al. 2014). Washburne ve Wall (1980) Afrika kökenli Amerikalıların, beyaz ırka oranla daha az açıkhava rekreasyonu etkinliklerine katıldıklarını iddia etmektedir. Yazarlara göre bu durumun nedeni, Afrika kökenli Amerikalıların açıkhava rekreasyon etkinliklerine katılmada daha fazla engel algıladıkları yönündedir (Akt. Shinew, Floyd \& Parry 2004). Covelli et al. (2007) ulusal orman kullanıcıları üzerine yaptıkları araştırmada, beyaz ırk olmayan katılımcıların algıladıkları engellerinin beyaz ırka oranla daha fazla olduğu belirlenmiştir. Çalışmanın sonuçlarına göre, kültürel nedenler ile birlikte enformasyon ve farkındalık konularında beyaz olmayan ırkın engelleri daha fazladır. Bu ve benzeri çalıştırmaları arttırmak mümkündür. Yapılan birçok çalışmada (Crespo et al. 2000; Sasidharan 2001; Green et al. 2012). Amerikan toplumundaki -etnik azınlıklar, kadınlar, kırsal alanda yaşayan bireyler ve yaşlı bireyler gibimarjinal grup olarak adlandırılanların, karşıtlarına oranla Açıkhava etkinliklerine katılmada daha isteksiz oldukları belirtilerek, bu grupların Açıkhava rekreasyonu etkinliklerine katılmada daha fazla kısıtlara/bariyerlere sahip olduğu belirtilmektedir.

Marjinal grupların, serbest zaman ve açıkhava rekreasyonu engelleri/kisıtllıklarının nedenini açıklamak için Marjinallik ve Etnik Köken hipotezlerine başvurulmuştur. Marjinallik hipotezi, azınlıkların etkinliklere düşük düzeyde katılımlarını açıklarken, sahip olunan azınlık statüsüne vurgu yapmaktadır. Başka bir açıklamayla, ikinci sınıf pozisyona sahip olan azınlıklar, toplumun geneline sınırlı düzeyde ulaşabilirler, bu durumda, serbest zaman ve rekreasyon etkinliklerine katılımı azaltır (Floyd et al. 1994). Etnik köken veya alt-kültür olarak bilinen ikinci hipotez ise, etkinliklere katılım düzeyi az olan azınlıkları veya sosyal düzenleri, normlar ve değer sistemleri olan ırksal veya etnik gruplar arasında farklılıklardan kaynaklandığını belirtmektedir. Bu açıklama sosyo-ekonomik duruma bakmaksızın, kültürel süreçlerin serbest zaman etkinliklerine katılımı daha fazla etkilediğini ileri sürmektedir. Başka bir deyişle, sahip olunan kültürel değerlerin, bu kültürel sahip olan alt-kültüre ait kişilerin rekreasyon davranışını etkilemektedir. İlgili literatür incelendiğinde, marjinallik (Washburne 1978; Woodard 1988; West 1989) ve etnik köken (Stamps \& Stamps 1985) hipotezlerinin çeşitli araştırmalarla desteklendiği görülmektedir. Dahası sosyo-psikolojik faktörlerin azınlıkların açıkhava rekreasyon etkinliklerine katılımını etkileyen engelleri anlamak için bir araç olabileceği iddia edilmiştir.

\section{Milli Park Kullanım Engellerine Yönelik Literatür}

Milli parklar, önemli açıkhava rekreasyonu ve turizm alanlarıdır. $\mathrm{Bu}$ nedenle, milli park kullanımına yönelik engellere ait çalışmaların açıkhava rekreasyonu engellerine yönelik çalışmalarla benzerlik göstermesi oldukça doğal karşılanmaktadır. Ancak milli park alanlarının 
yapıları itibari ile çeşitli özellikler taşıması, çoğunluğunun kırsal alanda bulunması gibi diğer açıkhava rekreasyonu etkinliklerinin gerçekleştiği alanlardan farklılıkları bulunmaktadır. $\mathrm{Bu}$ bağlamda, ilgili literatür incelendiğinde, milli park kullanımı engelleri özelinde azda olsa çalışma vardır. Bu çalışmalar Tablo 6'da özetlenmiştir.

Tablo 6. Milli Park Kullanım Engellerine ait Literatür Özeti

\begin{tabular}{|c|c|c|c|c|}
\hline Yazar/lar & $\begin{array}{l}\text { Araştırma Kapsamı/ } \\
\text { İncelenen Değişkenler }\end{array}$ & Yöntem & $\begin{array}{c}\text { Örneklem } \\
\text { Hacmi }\end{array}$ & Sonuç/ Kısıtlar \\
\hline $\begin{array}{l}\text { Lawton \& } \\
\text { Weaver } \\
\text { (2008) }\end{array}$ & Yerel halk & $\begin{array}{l}\text {-Anket } \\
\text {-Hiyerarşik } \\
\text { Kümeleme } \\
\text { Analizi }\end{array}$ & 455 kişi & $\begin{array}{l}\text { 1.Küme: Erteleyen kişiler } \\
\text { Ziyarete istekli ancak henüz } \\
\text { gerçekleştirmemiş } \\
\text { 2.Küme: Farkında olmayan kişiler } \\
\text { Parkın varlığından haberdar değil } \\
\text { 3.Küme: Çoklu-Engellenmiş Kişiler } \\
\text { İçsel, Kişilerarası ve Yapsal Engeller }\end{array}$ \\
\hline $\begin{array}{l}\text { Roberts \& } \\
\text { Rodriguez } \\
\text { (2008) }\end{array}$ & $\begin{array}{l}\text { Afrika-Amerikan ve } \\
\text { Latin Ziyaretçiler }\end{array}$ & $\begin{array}{l}\text {-Delphi } \\
\text { Tekniği } \\
\text { *Odak } \\
\text { Grup }\end{array}$ & 70 kişi & $\begin{array}{l}\text { Her iki teknik ile elde edilen ortak } \\
\text { engeller } \\
\text { 1.İçsel; bilgilendirme eksikliği } \\
\text { 2.Kişilerarası; Kişisel } \\
\text { raharsızlık/güvenlik problemleri ve } \\
\text { sosyalleşme } \\
\text { 3.Yapısal; Milli park sevisinin kültürü, } \\
\text { algılanan ayrımcılık, tarihi yapı }\end{array}$ \\
\hline $\begin{array}{l}\text { Roberts } \\
(2007)\end{array}$ & Etnik Azınlıklar & Odak Grup & 99 kişi & $\begin{array}{l}\text { 1.Ulaşılabilirlik } \\
\text { Ulaşım konuları } \\
\text { Maliyet } \\
\text { Güvenlik ve korku } \\
\text { 2.İletişim } \\
\text { 3.Kültürel farklılıklar } \\
\text { Algılanan Önyargı, Ayrıştırma } \\
\text { 4.Bilgi, Deneyim, Farkındalık Eksikliğ } \\
\text { 5.Temsil Edilme (Personel olarak etnik } \\
\text { azınlıkların olmaması) }\end{array}$ \\
\hline $\begin{array}{l}\text { Weber \& } \\
\text { Sultana (2013) }\end{array}$ & $\begin{array}{l}\text {-Azınlıklar } \\
\text {-Coğrafik uzaklığın } \\
\text { azınlıkların park } \\
\text { ziyaretine etkisi }\end{array}$ & $\begin{array}{l}\text {-Coğrafi } \\
\text { Bilgi } \\
\text { Sistemi } \\
\text {-Ikincil } \\
\text { Veri } \\
\end{array}$ & 285 park & $\begin{array}{l}\text { Azınlıkların lokasyonları ile park } \\
\text { ziyaretleri arasında kuvvetli ilişki }\end{array}$ \\
\hline $\begin{array}{l}\text { Le \& Holmes } \\
\text { (2012) }\end{array}$ & $\begin{array}{l}\text { Afrika-Amerikan } \\
\text { Bireyler }\end{array}$ & Odak Grup & $\begin{array}{l}\text { 6-12 kişi } \\
\text { x10 Odak } \\
\text { Grup }\end{array}$ & $\begin{array}{l}\text { 1.Bilgilendirme eksikliği } \\
\text { 2.Bilinmeye karşı korku ve doğaya } \\
\text { karşı mesafeli olma } \\
\text { 3.Ekonomik kıstlar } \\
\text { 4.Algılanan ayrımcılı//rkçılık }\end{array}$ \\
\hline $\begin{array}{l}\text { Butler \& } \\
\text { Richardson } \\
\text { (2015) }\end{array}$ & $\begin{array}{l}\text { Siyahi Güney } \\
\text { Afrikalılar }\end{array}$ & $\begin{array}{l}\text {-Anket } \\
\text {-Yarı- } \\
\text { yapılan- } \\
\text { dırılmış } \\
\text { Mülakat }\end{array}$ & 466 kişi & $\begin{array}{l}\text { 1.Ekonomik engeller } \\
\text { 2.Uzaklık } \\
\text { 3.Ulaşımın olmayışı } \\
\text { 4.Zaman } \\
\text { 5.Organize turların olmayışı }\end{array}$ \\
\hline $\begin{array}{l}\text { Kruger \& } \\
\text { Dougler } \\
\text { (2015) }\end{array}$ & Siyahi İç Pazar & Anket & 350 kişi & $\begin{array}{l}\text { Yapisal Engeller } \\
\text { 1.Pahal1lık } \\
\text { 2.Zaman }\end{array}$ \\
\hline
\end{tabular}




\begin{tabular}{|c|c|c|c|c|}
\hline & & & & $\begin{array}{l}\text { 3.Uzaklık } \\
\text { Içsel Engeller } \\
\text { 1.Aile bireylerinin ilgisinin olmaması }\end{array}$ \\
\hline Thapa (2012) & $\begin{array}{l}\text {-Yerli ve yabancı } \\
\text { ziyaretçiler } \\
\text {-Yapısal Engeller }\end{array}$ & Anket & 2395 kişi & $\begin{array}{l}\text { Yabancı Ziyaretçilere göre } \\
\text { Kişisel Yapısal Engeller } \\
\text { 1.Kişisel güvenlik korkusu } \\
\text { 2.Yetersiz Zaman } \\
\text { 3.İlgi olmaması } \\
\text { Çevresel Yapısal Engeller } \\
\text { 1.Kalitesiz konaklama hizmeti } \\
\text { 2.Uygun bilgilendirme eksikliği } \\
\text { 3.Kötü hava koşulları } \\
\text { Yerli Ziyaretçilere göre } \\
\text { 1.Finansal maliyet } \\
\text { 2.Kötü yol durumu }\end{array}$ \\
\hline $\begin{array}{l}\text { Weaver } \\
\text { (2015) }\end{array}$ & $\begin{array}{l}\text {-Yerli Ziyaretçiler } \\
\text {-Gönüllü Turizmi }\end{array}$ & Anket & 804 & $\begin{array}{l}\text { 1.Uzakl1k } \\
\text { 2.Zaman }\end{array}$ \\
\hline $\begin{array}{l}\text { Ostergren, } \\
\text { Solop \& } \\
\text { Hagen (2005) }\end{array}$ & $\begin{array}{l}\text {-Yerel Halk } \\
\text {-MP Giriş Ücreti }\end{array}$ & Anket & 3519 & $\begin{array}{l}\text { Toplam seyahat giderleri içerisinde } \\
\text { giriş ücretleri engel/kısıt olmadığ } \\
\text { belirlenmiştir. }\end{array}$ \\
\hline
\end{tabular}

Önemli bir açıkhava rekreasyonu ve turizm alanı olan milli parklara yönelik engellerin irdelendiği bu çalışmada, milli park kullanımlarına ait engellerinin çoğunlukla açıkhava rekreasyonu engellerine benzerlik gösterdiği belirlenmiştir. Bu benzerlik, belirli düzeyde kabul edilebilir olmasına rağmen milli park özellinde yapılmış olan engellere yönetlik çalışmaların sınırlı olduğu düşünülmektedir. İlgili literatür incelendiğinde, engellere yönelik sınıflamanın çoğunlukla, kişisel, kişiler arası ve yapısal engeller biçiminde olduğu söylenebilir. Bu boyutlar yukarıda da bahsedildiği gibi açıkhava engelleriyle hatta sersest zaman engelleriyle paralellik göstermektedir. Ancak yapılan çalışmalar, milli parklara yönelik engellerin, yapısal engeller çatısı altında daha fazla yoğunlaştığını göstermektedir. Bu durumun nedeninin, milli parkların, çoğunlukla kırsal alanda bulunmasından kaynaklı olduğu düşünülmektedir. Çoğunlukla kırsal alanda olan milli parklar, bulundukları konumlar itibari ile ulaşım ve bununla bağlantılı olarak zaman problemleri yaratırken, giriş ücretleri ile de ekonomik maliyetler oluşturmaktadır. İlgili literatürün de (Ostergren, Solop \& Hagen 2005; Roberts 2007; Le \& Holmes 2012; Thapa 2012; Weber \& Sultana 2013; Butler \& Richardson 2015; Kruger \& Dougler 2015; Weaver 2015) bu iki yapısal engel üzerine sonuçlar saptadığı görülmektedir.

Literatürdeki çalışmaların yoğunlaştığı diğer bir kavram ise, çalışmaların evrenleri ile ilgilidir. Yapılan birçok araştırmada (Roberts 2007; Roberts \& Rodriguez 2008; Le \& Holmes 2012; Weber \& Sultana 2013; Butler \& Richardson 2015; Kruger \& Dougler 2015) etnik azınlıklar üzerine odaklanıldığı görülmektdir. Bu durum, açıkhava rekreasyonu ve serbest zaman engelleri çalışmaları ile paraleldir. Her iki kavram ile ilgili yapılan öncül çalışmaların ırk yani etkin köken ve bununla bağlantılı olarak azınlıklar özelinde yoğunlaştığı, bunun nedenininde sosyal eşitsizliğin bu grupları daha fazla etkilediği görüşüdür. Bu kapsamda, milli parklar özelinde de aynı nedenden ötürü daha fazla çalışma yapıldığı düşünülmektedir.

Milli park kullanım engelleri araştırmalarındaki diğer bir konu ise, kullanıcılara yöneliktir. Çalışmaların, yerel halk ve turistler olarak sınıflandığ 1 , bazı çalışmarın yerel halk özelinde (Ostergren, Solop \& Hagen 2005; Lawton \& Weaver 2008), bazılarınında her iki grubu da (Thapa 2012; Weaver 2015) kapsayacak biçimde tasarlandığı görülmektedir. Bu iki grubun 
farklı engellere sahip olacağı düşünüldüğünde, özellikle planlama çalışmaları için her iki gruba yönelik engellerin belirlenmesinin gerektiği düşünülmektedir.

Sonuç olarak yapılan çalışmada, milli parklar özelinde yapılmış olan çalışmaların sınırlı olduğu belirlenmiştir. Milli parklar, önemli açıkhava rekreasyonu kaynakları olsalar bile yapıları itibari ile diğer açıkhava rekreasyonu etkinliklerinin gerçekleştiği alanlardan farklılık barındırmaktadırlar. $\mathrm{Bu}$ nedenle, milli park engellerine yönelik çalışmaların açıkhava rekreasyonu engelleri çalışmalarından ayrı tutulmaları ve bu çalışmaların kendi özelinde gerçekleştirilmeleri önerilmektedir. Ayrıca gerçekleştirilecek olan çalışmaların, yaygın etki yaratacak biçimde, hem yerel halk hemde turistlere yönelik tasarlanması gereklidir. Özellikle milli parkların etkin ve verimli kullanılmadığı bölgelerde, bu alanların kullanılmasına engel olan faktörlerin tespit edilmesi, bu alanların daha sürdürülebilir kullanılmasına katkı sağlayabilir. Bu sayede, bir yandan doğa koruma çalışmalarına destek olunurken, diğer yandan da makro ve mikro düzeyde ekonomik fayda sağlanacak ve de toplumun fizyolojik, psikolojik, sosyo-kültürel birçok ihtiyacı karşılanabilecektir.

\section{KAYNAKÇA}

Akesen A. (1982). “Rekreasyonel Taşıma Kapasitesi ve Açıkhava Rekreasyonu Planlamasindaki Önemi”. İstanbul Üniversitesi Orman Fakültesi Dergisi 32/1(1982) 216-223.

Alexandris K. \& Carroll B. (1997). "Demographic Differences in the Perception of Constraints on Recreational Sport Participation: Results from a Study in Greece”. Leisure Studies 16 (1997) 107-126.

Anonim (2005). The Health and Social Benefits of Recreation: An Element of the California Outdoor Recreation Planning Program. California 2005.

Boothy J., M. F. Tungatt \& A. R. Townsend. (1981). "Ceasing Participation in Sports Activity: Reported Reasons and Their Implications”. Journal of Leisure Research 13 (1981) 1-14.

Butler G. \& Richardson S. (2015). "Barriers to Visiting South Africa's National Parks in the Postapartheid Era: Black South African Perspectives from Soweto”. Journal of Sustainable Tourism 23/1 (2015) 146-166.

Caber M. \& Albayrak T. (2006). "Testing the Hierarchical Leisure Constraints Model in Nature-Based Tourism in Turkey”. GEOTOUR (2006) 134-141.

Çetinkaya G. (2008). Milli parklarin bir Rekreasyon Alanı Olarak Düzenlenmesi ve Yönetilmesi: Bir Model Önerisi. Yayımlanmamış Yüksek Lisans Tezi. Akdeniz Üniversitesi, Sosyal Bilimler Enstitüsü, Antalya 2008.

Cole D. N. (1989). "Recreation Ecology: What We Know, What Geographers can Contribute". Professional Geographer 41/2 (1989) 143-148.

Cordell H. K. (2008). “The Latest on Trends in Nature-Based Outdoor Recreation”. Forest History Today Spring (2008) 4-10.

Covelli E. A., Burns R. C. \& Graefe A. (2007). "Perceived Constraints by Non-Traditional Users on the Mt. Baker-Snoqualmie National Forest”. Eds. R. Burns \& K. Robinson. Proceedings of the 2006 Northeastern Recreation Research Symposium. Newtown Square, PA (2007) 422-429.

Crawford D. J. E. \& Godbey G. (1991). A Hierarchical Model of Leisure Constraints. Journal of Leisure Sciences 13 (1991) 309-320.

Crespo C. J., Smit E., Andersen R. E., Carter-Pokras O. \& Ainsworth B. E. (2000). "Race/Ethnicity, Social Class and Their Relation to Physical Inactivity During Leisure Time: Results from the Third National Health And Nutrition Examination Survey, 1988-1994”. American Journal of Preventive Medicine 18 (2000) 46-53.

Demir C. (2001). Milli Parklarda Turizm ve Rekreasyon Faaliyetlerinin Sürdürürülebilirliği: Türkiye'deki Milli Parklara Yönelik Bir Uygulama. Yayımlanmamış Doktora Tezi. Dokuz Eylül Üniversitesi, Sosyal Bilimler Enstitüsü, İzmir 2001. 
Dilsaver L. M. (1994). America's National Park System: The Critical Documents. USA 1994.

Doğa Koruma ve Milli Parklar Genel Müdürlüğü Resmi İnternet Sitesi. (2015, Mayıs 19) Kaynak: http://www.milliparklar.gov.tr/mp/mp.pdf

Doğa Koruma ve Milli Parklar Genel Müdürlüğü Resmi İnternet Sitesi. (2015, Mayıs 19) Kaynak: http://www.milliparklar.gov.tr/mp/hrt.htm

Doğa Koruma ve Milli Parklar Genel Müdürlüğü Resmi İnternet Sitesi. (2016, Ocak 05) Kaynak: http://www.milliparklar.gov.tr/anasayfa/resimlihaber/15-09-15/M\%C4\%B0LL\%C4\%B0_PARKLA RA_Z\%C4\%B0YARET\%C3\%87\%C4\%B0_AKINI.aspx?sflang=tr.

Doğaner S. (1985). Turizmde Doğanın Önemi ve Türkiye'de Doğayı Koruma Çalışmaları. Cilt:2, Sayı:2. İstanbul 1985.

Eagles P. F. J. \& McCool S. F. (2002). Tourism in National Parks and Protected Areas- Planning and Management. UK 2002.

Eagles P. F. J. \& McCool S. (2004). Tourism in National Parks and Protected Areas Planning and Management. UK 2004.

Eagles P. F. J., McLean D. \& Stabler M. J. (2000). "Estimating the Tourism Volume and Value in Parks and Protected Areas in Canada and the USA". George Wright Forum 17/3 (2000) 62-82.

Floyd M. F., Nicholas L., Lee I., Lee J. H. \& Scott D. (2006). "Social Stratification in Recreational Fishing Participation Research and Policy Implications”. Leisure Sciences 28/4 (2006) 351-368.

Ghimire R., Green G. T., Poudyal N. C. \& Cordell H. K. (2014). “An Analysis of Perceived Constraints to Outdoor Recreaiton”. Journal of Park and Recreation Administration 32/4 (2014) 52-67.

Green G. T., Bowker J. M., Wang X., Cordell H. K. \& Johnson C. Y. (2012). "A National Study of Constraints to Participation in Outdoor Recreational Activities". Ed. H. K. Cordell. Outdoor Recreation Trends And Futures. Asheville, NC (2012) 70-74.

Hacioğlu N., Gökdeniz A. \& Dinç Y. (2003). Boş Zaman ve Rekreasyon Yönetimi Örnek Animasyon Uygulamaları. Ankara 2003.

Haennel R. G \& Lemire F. (2002). "Physical Activity to Prevent Cardiovascular Disease. How much is Enough?”. Canadian Family Physician 48 (2002) 65-71.

Harrison G. \& Erpelding M. (2012). Outdoor Progmram Administration: Principles and Practices. US 2012.

International Union for Conservation of Nature Resmi İnternet Sitesi. (2015, Mayıs 17) Kaynak: http://www.iucn.org/about/work/programmes/gpap_home/gpap_quality/gpap_pacategories/

Iso-Ahola S. E., Jackson E. \& Dunn E. (1994). "Starting, Ceasing, and Replacing Leisure Activities over the Life-Span”. Journal of Leisure Research 26/3 (1994) 227-249.

Jackson E. (1993). "Recognizing Patterns of Leisure Constraints: Results from Alternative Analyses". Journal of Leisure Research 25 (1993) 129-149.

Jackson E. L. \& Scott D. (1999). “Constraints to Leisure”. Eds. E. L. Jackson \& T. L. Burton. Leisure Studies: Prospects for the Twenty-First Century. State College, PA (1999) 167-175.

Karaküçük S. (1999). Rekreasyon Boş Zamanları Değerlendirme. Ankara 1999.

Kelly J. (1980). Recreation Trends Toward The Year 2000. Champaign, IL 1980.

Kelly J. (1996³). Leisure. Englewood Cliffs, NJ 1980.

Kruger E. A. \& Douglas A. (2015). "Constraints to Consumption of South Africa's National Parks Among the Emerging Domestic Tourism Market”. Development Southern Africa 32/3 (2015) 303-319.

Lawton L. J. \& Weaver D. B. (2008). "Factors Associated with Non-Visitation by Area to Congaree National Park, South Carolina”. Journal of Park and Recreation Administration 26/4 (2008) 66-82.

Le Y. \& Holmes N. C. (2012). "Barriers to a Backyard National Park: Case Study of African American Communities in Columbia, SC”. Journal of Ethnographic \& Qualitative Research 7 (2012) 20-35.

Lee J. H., Scott D. \& Floyd. M. F. (2001). "Structural Inequalities in Outdoor Recreation Participation: A Multiple Hierarchy Stratification Perspective”. Journal of Leisure Research 33/4 (2001) 427-449.

Manning R. \& Anderson L. E. (2012). Managing Outdoor Recreation: Case Studies in the National Parks. Cambridge 2012. 
Manning R., Jacobi C., Valliere W., Wang B. (1998). “Standards of Quality in Parks and Recreation”. Parks \& Recreation 33/7 (1998) 88-94.

Mayer M., Muller M., Woltering M., Arnegger J. \& Job H. (2010). “The Economic Impact of Touris in Six German National Parks”. Landscape and Urban Planning 97/2 (2010) 73-82.

McGuire F. A., Boyd R. K. \& Tedrick R. E. (1996). Leisure and Aging. Champain, IL 1996.

Mevzuatı Geliştirme ve Yayın Genel Müdürlüğü Resmi İnternet Sitesi. (2015, Haziran 03) Kaynak: http:// www.mevzuat.gov.tr/MevzuatMetin/1.5.2873.pdf.

Miller R. K. \& Washington K. (2014). Travel \& Tourism Market Research 2015-2016. US 2014.

National Park Service Resmi İnternet Sitesi. (2015, Mayıs 15) Kaynak: http://www.nps.gov/news/upload/ NPS-Overview-2015-update-2-25.pdf.

Nepal S. (2000). "Tourism in Protected Areas the Nepalese Himalaya”. Annals of Tourism Research 27/3 (2000) 661-681.

NETSAP (2004). National Ecotourism Strategy and Action Plan for Bulgaria. Ed. K. Georgieva. Sofia 2004.

Öcal K. (2012). "Ölçek Geliştirme: Serbest Zaman Fiziksel Aktivite Kısıtlayıcılar (SZFA-K)”. Spor Bilimleri Dergisi 23/2 (2012) 50-60.

Office For National Statistic Resmi İnternet Sitesi. (2015, Haziran 31) Kaynak: http://www.ons.gov.uk/ ons/guide-method/census/2011/uk-census/index.html

Ostergren D., Solop F. I. \& Hagen K. K. (2005). "National Park Services Fee: Value for the Money or a Barrier to Visitation?”. Journal of Park and Recreation Administration 18/1 (2005) 18-36.

Outdoor Industry Association. (2012). The Outdoor Recreation Economy. Washington, US 2012.

Raymore L. \& Scott D. (1998). "The Caharacteristics and Activities of Older Adult Visitors to a Metropolitan Park District”. Journal of Park and Recreation Administration 16 (1998) 1-21.

Reconomics (2014). The Economic Impact of Outdoor Recreation. UK 2014.

Roberts N. S. \& Rodriguez D. A. (2008). "Use of Multiple Methods: An Examination of Constraints Effecting Ethnic Minority Visitor Use of National Parks and Management Implicaitions”. Ethnic Studies Review 31/2 (2008) 35-70.

Roberts N. S. (2007). Visitor/Nonvisitor Use Constraints: Exploring Ethnic Minority Experiences and Perspectives. San Francisco, CA 2007.

Runte A. (2010). National Parks: The American Experience. Colorado 2010.

Sasidharan V. (2001). The Urban Recreation Experience: An Examination of Multicultural Differences in Park and Forest Visitation Characteristics. Unpublished Ph.D Thesis. The Pennsylvania State University, University Park, PA 2001.

Scott D. \& Munson W. (1994). "Perceived Constraints to Park Usage Among Individuals with Low Incomes”. Journal of Park and Recreation Administration 12/4 (1994) 79-96.

Scott D. \& Jackson E. (1996). "Factors that Limit and Strategies that Might Encourage People's Use of Public Parks”. Journal of Park and Recreation Administration 12 (1996) 79-96.

Shinew K. J., Floyd M. F. \& Parry D. (2004). "Understanding the Relationship Between Race and Leisure Activities and Constraints: Exploring an Alternative Framework". Leisure Sciences: An Interdisciplinary Journal 26/2 (2004) 181-199.

Shores K. A., Scott D. \& Floyd M. F. (2007). "Constraints to Outdoor Recreation: A Multiple Hierarchy Stratification Perspective”. Leisure Sciences: An Interdisciplinary Journal 29/3 (2007) 227-246.

Stamps S. M. \& Stamps M. B. (1985). "Race, Class and Leisure Activities of Urban Residents”. Journal of Leisure Research 17/1 (1985) 40-56.

Tarrant M. A., Manfredo M. J. \& Driver B. L. (1994). "Recollections of Outdoor Recreation Experiences: A Psycho-Physiological Perspective”. Journal of Leisure Research 26/4 (1994) 357-371.

Taylor D. W. (2004). "Managing the Visitor Experience within Europe’s Protected Areas”. UK 2004.

Thapa B. (2012). "Why Did They Not Visit? Examining Structural Constraints to Visit Kafue National Park, Zambia”. Journal of Ecotourism 11/1 (2012) 74-83.

Thapa B., Pennigton G L. \& Holland S. (2002). Assessing the Validity of an Outdoor Recreation 
Constrains Model for Tourists to Florida. Florida 2002.

The Statistics Portal Resmi İnternet Sitesi. (2015, Mayıs 15) Kaynak: http://www.statista.com/statistics/ 206820/number-of-visitors-to-national-park-service-sites-since-2010/.

Voth A. (2012). "National Parks and Rural Development in Spain”. Ed. I. Mose. Protected areas and regional development in Europe- towards a new model for the 21st century. USA (2012) 141-160.

Walker G. J. \& Virden R. J. (2005). “Constraints on Outdoor Recreation”. Ed. E. L. Jackson. Constraints to Leisure. State College, Penna (2005) 201-219

Washburne R. F. (1978). "Black Underparticipation in Wildland Recreation: Alternative Explanations". Leisure Sciences 1/2 (1978) 175-189.

Weaver D. (2015). "Volunteer Tourism and Beyond: Motivations and Barriers to Participation in Protected Area Enhancement”. Journal of Sustainable Tourism 23/5 (2015) 683-705.

Weber J. \& Sultana S. (2013). "Why do so few minority people visit national parks? Visitation and the accessibility of 'America's Best Idea,”. Annals of the Association of American Geographers 103/3 (2013) 437-464.

Welk G. \& Blair S. (2000). "Physical Activity Protects Against the Health Risks of Obesity”. President's Council on Physical Fitness \& Sport Research Digest 3/12 (2000) 1-8.

West P. C. (1989). "Urban Region Parks and Black Minorities: Subculture, Marginality, and Interracial Relations in Park Use in the Detroit Metropolitan Area”. Leisure sciences 11/1 (1989) 11-28.

White H. R. \& Bustam T. D. (2010). Using Leisure Constraints Research to Inform Outdoor Recreation Research and Natural Resource Management Decisions, In Park Break Perspectives. Michigan USA 2010.

Woodard M. D. (1988). "Class, Regionality, and Leisure Among Urban Black Americans: The Post-Civil Rights Era”. Journal of Leisure Research 20/2 (1988) 87-105.

WTTC (2015). Economic Impacts of Travel and Tourism, 2015 Annual. London 2015.

UNWTO (2015). Tourism Highlights 2015 Edition. Kaynak: http://www.e-unwto.org/doi/pdf/10.18111/ 9789284416899

Yücel M. \& Babuş D. (2005). “Doğa Korumanin Tarihçesi ve Türkiye’deki Gelişmeler”. Doğu Akdeniz Ormancılık Araştırma Müdürlüğ̈̈ DOA Dergisi 11 (2005) 151-175. 